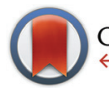

CrossMark $\leftarrow$ click for updates

Cite this: Polym. Chem., 2016, 7, 7204

Received 15th August 2016, Accepted 21st October 2016

DOI: 10.1039/c6py01418f

www.rsc.org/polymers

\section{A novel PEG-haloperidol conjugate with a non-degradable linker shows the feasibility of using polymer-drug conjugates in a non-prodrug fashion}

\author{
Felicity Heath, ${ }^{a}$ Amy Newman, ${ }^{a}$ Chiara Clementi, ${ }^{\mathrm{b}}$ Gianfranco Pasut, ${ }^{\mathrm{b}}$ Hong Lin, ${ }^{\mathrm{a}}$ \\ Gary J. Stephens, ${ }^{a}$ Benjamin J. Whalley, ${ }^{a}$ Helen M. I. Osborn ${ }^{a}$ and Francesca Greco ${ }^{a}$
}

\begin{abstract}
A PEG-haloperidol conjugate containing a non-biodegradable linker was synthesised. Incubation with rat plasma demonstrated excellent linker stability, and competition radioligand binding assays demonstrated retained binding to the $\mathrm{D}_{2}$-receptor. In silico studies predicted that the conjugate will not cross the blood-brain barrier (BBB), thus potentially restricting haloperidol action to one side of the $B B B$.
\end{abstract}

\section{Introduction}

Many drugs display an unfavourable body distribution, which results in unwanted exposure of healthy tissues to the drug. One such case applies to drugs that have their desired therapeutic target in the central nervous system (CNS) but display unwanted effects due to their peripheral action. An example is L-DOPA, used in the treatment of Parkinson's disease, which can cause nausea and vomiting as a result of stimulation of the peripheral dopamine receptors by its metabolite dopamine. ${ }^{1,2}$ The opposite is also true, in that some drugs acting in the peripheral tissues display unwanted effects centrally. First generation anti-histamines that are able to cross the blood brain barrier (BBB) are widely known to cause side effects of drowsiness. ${ }^{3,4}$ In both scenarios, preventing drug permeation across the $\mathrm{BBB}$ would effectively localise drug action to a single compartment: periphery following peripheral administration, or central, following central administration. Many factors affect drug permeability across the BBB (e.g. lipophilicity and hydrogen bonding capacity), but size is known to play a particularly crucial role.$^{5-7}$ Conjugation of a small, BBB-penetrating drug molecule to a polymer could restrict its transit across this barrier, thus removing any undesired effects in either compartment. Indeed, Satchi-Fainaro et al. have demon-

\footnotetext{
${ }^{a}$ Reading School of Pharmacy, PO Box 224, Reading, RG6 6AD, UK.

E-mail:f.greco@reading.ac.uk

${ }^{b}$ Dept. of Pharmaceutical Sciences, Via F. Marzolo 5, University of Padua,

35100 Padova, Italy
}

strated that conjugation of an anti-tumour agent, TNP-470, to an HPMA-copolymer resulted in a significant reduction in neurotoxicity compared to the free drug. These findings suggested that conjugation to the polymer prevented its BBB passage. ${ }^{8}$ However, the system was still not ideal as the drug (TNP-470) was conjugated via a degradable linker (a peptidyl linker). As such, this conjugate still had the potential for drug-related toxicity once the drug is released. More recently, a PEGylated opioid antagonist (Movantik ${ }^{\mathrm{TM}}$ ) has been marketed as a peripherally-acting opioid antagonist for the treatment of opioidinduced constipation. ${ }^{9}$ Further, Kopecek and colleagues have proposed "drug free" polymer-drug conjugates, in which the polymer is an active agent per $s e^{,} .^{10,11}$

The concept of restricting the action of a drug selectively to the periphery or to the CNS, by its covalent conjugation to a polymer, is scientifically appealing, but for this strategy to work two conditions must be met. First, the polymer must be able to prevent the drug from crossing the BBB. Second, the polymer conjugated drug must retain (at least partially) its biological activity. Meeting the first condition is very straightforward as it is well known that size is a key modulator of BBB permeation. ${ }^{12}$ The second condition is much more challenging and requires careful selection of an appropriate ligand.

This study explores, for the first time, application of this strategy to the dopaminergic system. In particular, we propose a polymer-drug conjugate that will: (a) be stable in biological fluids, thus preventing unwanted drug release from the conjugate, (b) retain some ability to modulate the dopaminergic system, (c) have a size compatible with what has been reported to be BBB non-permeable. To explore this hypothesis, the $\mathrm{D}_{2}$ receptor antagonist, haloperidol (Fig. 1) was selected for conjugation to a linear bifunctional PEG polymer.

This ligand presents a series of characteristics rendering it suitable for the proposed application, namely: (i) it is an antagonist of the chosen system (dopaminergic); (ii) as a free drug, it is able to cross the BBB; (iii) the hydroxyl group is a suitable point for conjugation; (iv) importantly, previous studies showing conjugation to affinity columns had shown an 


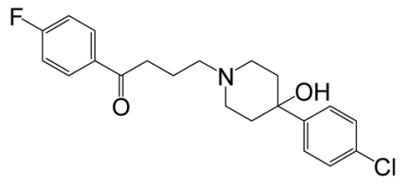

Fig. 1 Chemical structure of the $D_{2}$ receptor antagonist haloperidol.

indication of ability to maintain its binding capacity to the $\mathrm{D}_{2}$ receptor after conjugation to sepharose solid supports as affinity column ligand. ${ }^{13}$

The system proposed in this study differs dramatically from most of the polymer-small-drug conjugates being developed, as the latter typically act as prodrugs and generally require a biodegradable bond or linker between polymer and drug to exert their action. ${ }^{14-18}$ Conversely, here we suggest a non degradable polymer-drug conjugate, in which the size of the polymer matches that needed to prevent BBB crossing, and in which the conjugation has been carried out at a point that allows (at least partial) retention of activity. The pharmacological target of the conjugate presented in this work (the dopamine $\mathrm{D}_{2}$ receptor) has the advantage of being expressed both centrally ${ }^{19-21}$ and peripherally, ${ }^{21-24}$ and also of being easily accessible to polymer-drug conjugates as a result of its location, for instance, on the plasma membrane of neuronal cells.

In this paper we report the synthesis, characterisation and in vitro biological assessment of a polymer-haloperidol conjugate designed to inhibit passage across the BBB. First, we report PEGylation of the chosen drug. PEG was chosen as the polymeric component due to its favourable properties such as: prolonged residence in the body, decreased metabolic degradation of the attached drug and improved solubility. ${ }^{25,26}$ Then, stability of the bond between the polymer and the drug was assessed in vitro using rat plasma. The ability of the conjugate to bind to $\mathrm{D}_{2}$ receptors was determined using radioligand binding assays. Finally, a theoretical model was employed to investigate the likelihood of PEG conjugation restricting the passage of haloperidol across the BBB. As such, this study can be considered as the first stage in determining the feasibility of the polymer-haloperidol conjugate for selective delivery to the central or peripheral system, after which it will be pertinent to conclude whether in vivo studies would be warranted.

\section{Results and discussion}

\subsection{Synthesis and characterisation}

To synthesise the PEG-haloperidol conjugate, direct conjugation of haloperidol to PEG via its tertiary hydroxyl group was initially attempted using the methane sulfonate ester of bishydroxy PEG. However, no reaction was observed with haloperidol, presumably due to the sterically hindered nature of the hydroxyl group. To aid conjugation of haloperidol to PEG, an ethylenediamine linker was attached to the hydroxyl group through a carbamate bond, introducing an accessible amine handle for subsequent conjugation to a polymer (Fig. 2).

The conjugation of haloperidol to a drug delivery carrier has not been extensively explored within the literature. Most


D

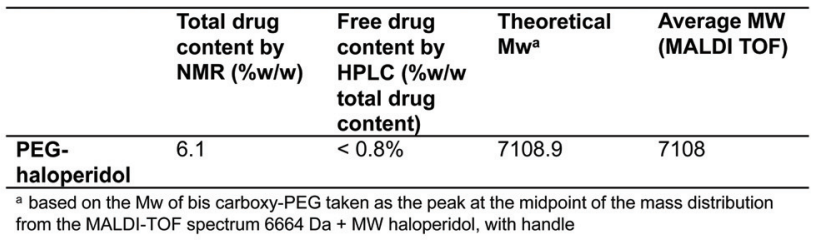

Fig. 2 Panel A: Synthetic scheme of haloperidol-amino ethyl carbamate (haloperidol-AEC) (I), and PEG-haloperidol (III), Panel B: ${ }^{1} \mathrm{H}-\mathrm{NMR}$ spectrum of PEG-haloperidol, Panel C: $C_{18}$ HPLC chromatogram of PEG-haloperidol ( $t_{R}=17.2 \mathrm{~min}$ ) and free haloperidol $\left(t_{\mathrm{R}}=16.1\right)$, Panel D: Characterisation of PEG-haloperidol. 
examples of derivatisation of haloperidol at the hydroxyl group involve the formation of an ester bond. ${ }^{27-30}$ This is likely to be susceptible to degradation by esterases in vivo ${ }^{31}$ and hence would not be suitable for this study. Therefore we examined a carbamate linkage which was anticipated to be more stable. $^{31,32}$

A method was developed for synthesis of the haloperidolpolymer conjugate that involved activation of haloperidol with $p$-nitrophenyl chloroformate, prior to reaction with ethylenediamine to give haloperidol amino-ethyl carbamate (haloperidol-AEC) (Fig. 2A). An excess of ethylene diamine was used to limit coupling of haloperidol to both ends of the linker. This reaction produced the target compound in a good yield of $49 \%$.

The subsequent conjugation strategy involved reaction of the derivatised ligand with bis-carboxy PEG through the use of widely exploited carbodiimide coupling chemistry (Fig. 2). PEG-haloperidol was successfully synthesised, as verified by ${ }^{1} \mathrm{H}$ and ${ }^{13} \mathrm{C}$ NMR spectroscopic analysis, which showed evidence of the characteristic peaks of haloperidol and PEG (Fig. 2B). Also, MALDI TOF analysis showed a shift in the mass distribution of the conjugates to higher masses compared to unmodified PEG, mirroring the degree of ligand loading (Fig. 2D).

Total haloperidol content was determined using ${ }^{1} \mathrm{H}$ NMR spectroscopic analysis. For the NMR analysis, ratios were determined for the peak areas representing the aromatic protons of haloperidol between 8.2-6 ppm and the peak areas of PEG protons from 3.8-3.4 ppm (Fig. 2B). PEG-haloperidol showed a loading of $6.1 \% \mathrm{w} / \mathrm{w}$. The polymer conjugate was purified by precipitation in diethyl ether, followed by dialysis against water which gave a low residual free drug content of less than $0.8 \% \mathrm{w} / \mathrm{w}$ (of total drug), determined by RP-HPLC.

\subsection{Stability of conjugate in plasma}

For our proposed strategy to be effective, formation of a stable bond between the drug and the polymer is essential, as a biodegradable bond would result in drug release and subsequent crossing of the $\mathrm{BBB}$, thus defeating the purpose of conjugation. Conjugate stability was tested in vitro upon incubation with rat plasma in order to probe stability under physiological conditions. Stability was assessed using HPLC to measure the amount of haloperidol released after incubation for varying lengths of time. Pleasingly, the conjugate proved stable when challenged with biological fluids. In particular PEG-haloperidol showed release of only $1 \%$ free haloperidol at $72 \mathrm{~h}$, increasing up to only $2 \%$ after 1 week (Fig. 3 ). Interestingly, it was observed that the point of cleavage was at the carbamate bond in the haloperidol-AEC structure, shown by RP-HPLC with the release corresponding to free haloperidol, rather than free haloperidol-AEC (data not shown).

\subsection{Assessment of the binding to the dopamine $D_{2}$ receptor in vitro}

The ability of the ligands to maintain some binding to $D_{2}$ receptors after conjugation to PEG was crucial for our hypoth-



Fig. 3 Stability of PEG-haloperidol conjugate on incubation with rat plasma. Data expressed as mean $\pm \operatorname{SEM}(n=3)$. Error bars hidden by the symbols when not visible.

esis to be viable, and hence worthy of future in vivo studies. The vast majority of polymer-drug conjugates rely on drug release to trigger biological effects. Therefore, it was essential to determine whether affinity of the conjugate for the $\mathrm{D}_{2}$ receptor was retained, and this was assessed by quantifying PEGhaloperidol's ability to displace the $\left[{ }^{3} \mathrm{H}\right]$ spiperone agonist binding in membrane preparations from Chinese hamster ovary $(\mathrm{CHO})$ cells stably expressing $\mathrm{D}_{2}$ receptors. Dopamine was used as a positive control $\left(\mathrm{p} K_{\mathrm{i}}=6.22 \pm 0.09, n=3\right)$ and PEG as a negative control (Fig. 4a).
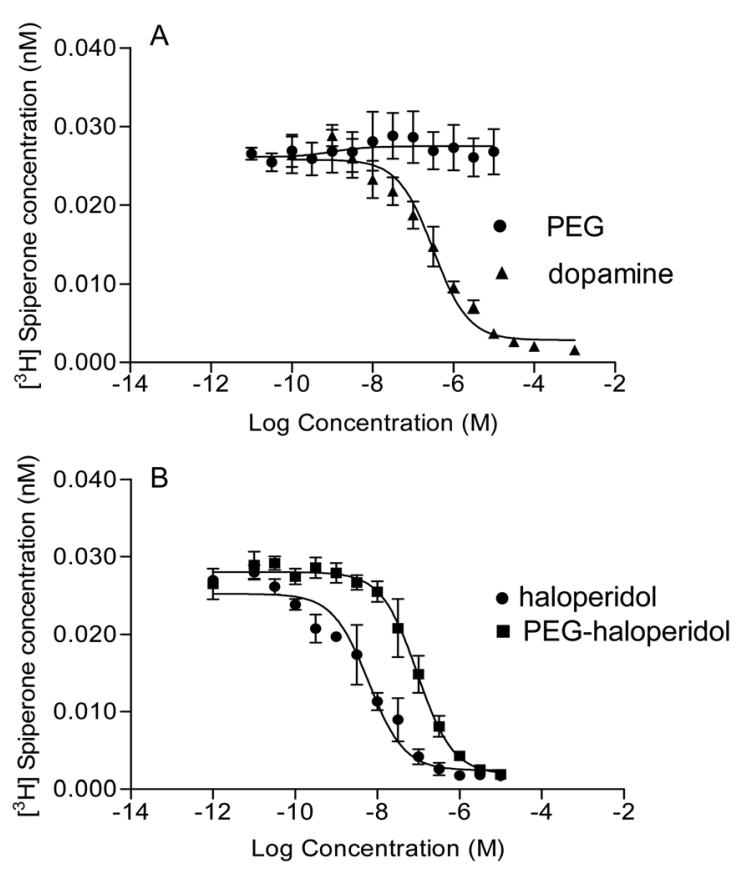

Fig. 4 Binding curves for compounds competing with $\left[{ }^{3} \mathrm{H}\right]$ spiperone in $D_{2}$ receptors from $\mathrm{CHO}$ cells: (a) PEG, negative control and dopamine, positive control, (b) PEG-haloperidol and free haloperidol. Data expressed as the mean $\pm \mathrm{SEM},(n=3) . \mathrm{p} K_{\mathrm{i}}$ values were derived from data fitted to a single-binding site model. 
PEG-haloperidol was able to retain affinity for the $\mathrm{D}_{2}$ receptor, albeit with a lower $\mathrm{p} K_{\mathrm{i}}(6.92 \pm 0.06, n=3)$ compared to free haloperidol (8.05 $\pm 0.19, n=3)$ (Fig. 4b). This reduction is in line with a previous report measuring BSA-conjugated haloperidol binding to the $\mathrm{D}_{2}$ receptor ${ }^{13}$ and as the binding is still sub-micromolar, it indicates potential for future applications.

\subsection{Theoretical modelling to assess the ability of PEG conjugation to restrict passage of $\mathrm{D}_{2}$ receptor ligands across the $\mathrm{BBB}$}

It has long been known that large molecules are generally unable to cross the BBB. In particular, a MW of 400-600 is normally considered the upper limit for crossing the BBB. ${ }^{33-35}$ As the conjugate described in this study has a MW $>$ than $6000 \mathrm{~g}$ $\mathrm{mol}^{-1}$ and is therefore well above this threshold, a gross restriction in its passive diffusion across the $\mathrm{BBB}$ is anticipated. However, to support this further, theoretical calculations were carried out using a model, proposed by $\mathrm{Fu}$ et al. ${ }^{36}$ (see section 4.10). The model predicts a log value of the ratio of concentration of compound in the brain:blood and has been employed in order to examine the hypothesis proposed in this paper; that the conjugation of haloperidol to PEG 6000 will inhibit its ability to cross the BBB.

The model predicts that haloperidol would be able to cross the BBB, which is well known and supported by experimental evidence. ${ }^{37}$ However, conjugation of haloperidol to PEG leads to a large reduction in the blood to brain concentration ratio predicted by the model (log BB shifting from 0.11 for haloperidol to -484.32 for the conjugate, Table 1), which means an overwhelming bias towards localisation within the blood.

It should be noted that the model used by Fu et al. was derived from a training set of 78 small molecule compounds using stepwise multiple regression analysis. The leave one out procedure was used to cross validate the model. While the model was developed from a range of small molecules, Fu et al. did not apply any restrictions with respect to the validity of their system for larger molecules, and indeed, molecular weight is one of the key parameters in their equation. Conversely, $\mathrm{Fu}$ et al. highlight that their equation only accounts for passive diffusion and that any compounds that are affected by P-glycoprotein efflux transporter are likely to be less well predicted. However, these limitations are unlikely to affect the predictions obtained for our system because haloperidol itself is known to be an inhibitor and not a substrate for P-glycoprotein efflux ${ }^{38,39}$ and PEG is thought to also have some inhibitory properties on P-glycoprotein. ${ }^{40}$

Table 1 Calculated log BB values for haloperidol and PEG-haloperidol conjugate

\begin{tabular}{lcrr}
\hline Compound & $M_{\mathrm{w}}$ & $n_{\mathrm{pol}}$ & $\log \mathrm{BB}^{a}$ \\
\hline Haloperidol & 375.9 & 5 & 0.11 \\
PEG-haloperidol & 7108 & 156 & -484.32 \\
${ }^{a}$ Calculated using eqn (1). & & &
\end{tabular}

These theoretical predictions highlight the significant change in properties (with respect to size, hydrogen bond forming potential and lipophilicity) conferred to haloperidol upon conjugation to PEG. The theoretical modelling indicates that the PEG bound haloperidol would substantially restrict the passage of the haloperidol across the BBB.

Stimulation of dopamine receptors present in either the CNS or the periphery can result in a diverse spectrum of effects depending on the location of the receptor making this system an ideal model for the proposed strategy. For example, in the brain, dopamine plays a role in the control of movement and behaviour, ${ }^{4-44}$ whereas, in the periphery, dopamine can affect the control of cardiovascular and renal function and hormone secretion. ${ }^{21,22,24,45}$ The ability to de-couple peripheral from central effects, through the proposed size exclusion mediated system, is certainly a powerful tool for investigative purposes. In addition, a conjugate able to elicit selective central or peripheral responses could potentially be used in in vivo models to mimic pathological conditions characterised by a selectively increased or decreased dopaminergic tone.

\section{Conclusions}

In this paper we present for the first time the synthesis and in vitro biological investigation of a PEG-haloperidol conjugate for use as an agent per se rather than in the conventional pro-drug fashion. The challenge of this study was to generate a stable derivative that would be expected to be $\mathrm{BBB}$ non-permeable whilst retaining some affinity for the target receptor.

A PEG-haloperidol conjugate was successfully synthesised and characterised. The conjugate displayed excellent stability, upon challenge with simulated physiological conditions. Radioligand binding studies showed that PEG-haloperidol was still able to bind to the $\mathrm{D}_{2}$ receptor albeit with a lower affinity compared to the free ligand. Theoretical modelling suggested that the conjugate would dramatically restrict the passage of haloperidol across the BBB. Taken together these results indicate that the PEG-haloperidol conjugate warrants future in vivo investigation, in the context of developing a system able to selectively (peripherally or centrally) modulate the dopaminergic system.

\section{Experimental section}

\subsection{Materials}

Alpha, omega-bis-carboxy PEG ( $\approx 6000 \mathrm{Da})$ was purchased from Iris Biotech $\mathrm{GmbH}$, Germany. All other chemicals and anhydrous solvents were purchased from Sigma Aldrich, apart from extra dry chloroform and sodium trifluoroacetate for MALDI-TOF-MS analysis which were purchased from Acros Organics. Other solvents were supplied by Fisher Scientific and deuterated solvents for NMR analysis were from 
Cambridge Isotope Laboratories. Rat plasma was obtained from whole blood taken from male Wistar rats, $P>21$ (Harlan, UK), which was subsequently spun at 3,500 rpm for $10 \mathrm{~min}$ and the plasma removed. Animals were humanely dispatched by a Schedule 1 (Animals Scientific Procedures Act, 1986) method prior to blood collection.

\subsection{Instrumentation and software}

${ }^{1} \mathrm{H}$ NMR and ${ }^{13} \mathrm{C}$ NMR spectra were obtained using Bruker spectrometers operating at either $700 \mathrm{MHz}$ or $400 \mathrm{MHz}$ and processed using Topspin software. Spectra were analysed using ACD/SpecManager software Version 12.01. HPLC analysis was performed on a Hewlett Packard series 1100 instrument equipped with an ACE C18 reverse phase column (300 $\mu \mathrm{m}$, $250 \times 4.6 \mathrm{~mm}$ ) (Hichrom, UK). MALDI-TOF spectra were obtained on a Bruker Ultraflex MALDI-TOF/TOF mass spectrometer. The MALDI data were processed using Bruker Daltonics, FlexAnalysis version 3.0 software. Radioligand competition binding assay results were analysed using GraphPad Prism software, version 5.04.

\subsection{Modification of haloperidol to contain an amine handle}

Haloperidol (150 mg, $0.4 \mathrm{mmol}$ ) was dissolved in anhydrous $\mathrm{CH}_{2} \mathrm{Cl}_{2}(10 \mathrm{~mL})$. To the solution, $p$-nitrophenyl chloroformate (160 mg, $0.8 \mathrm{mmol})$ and triethylamine $(139 \mu \mathrm{L}, 1.0 \mathrm{mmol})$ were added. The reaction was stirred for one hour at room temperature and then added drop wise to a solution of ethylenediamine $(267 \mu \mathrm{L}, 4 \mathrm{mmol})$ in DMF $(20 \mathrm{~mL})$. The reaction was stirred overnight and monitored by RP-HPLC. The haloperidol-amino ethyl carbamate (haloperidol-AEC) product was purified by washing with $0.1 \mathrm{M}$ sodium hydrocarbonate $(3 \times 200 \mathrm{~mL})$, followed by chromatography on a $\mathrm{SiO}_{2}$ column $(30 \times 2.5 \mathrm{~cm})$ eluted with a chloroform-methanol mixture (90:10 to only methanol) and determined by TLC analysis (yield 49\%). Successful synthesis was confirmed using HPLC and ${ }^{1} \mathrm{H}$ and ${ }^{13} \mathrm{C}$ NMR spectroscopic analysis. The introduction of free amine groups was verified using the 2,4,6-trintirobenzenesulfonic acid assay. ${ }^{46}$

${ }^{1} \mathrm{H}$ NMR $\left(\mathrm{CDCl}_{3}, 400 \mathrm{MHz}\right): 8.04\left(1 \mathrm{H}, \mathrm{s}, \mathrm{C}=\mathrm{O}(\mathrm{NH}) \mathrm{CH}_{2}\right)$, $7.93\left(2 \mathrm{H}, \mathrm{dd}, J_{\mathrm{ab}}=9.0 \mathrm{~Hz}, J_{\mathrm{aF}}=5.5 \mathrm{~Hz}, \mathrm{Ar}-\mathrm{F}\right), 7.22(4 \mathrm{H}, \mathrm{dd}, J=$ $9.5 \mathrm{~Hz}, J=9.0 \mathrm{~Hz}, \mathrm{Ar}-\mathrm{Cl}), 7.05-7.03(2 \mathrm{H}, \mathrm{m}, \mathrm{Ar}-\mathrm{F}), 5.20-5.10$ $\left(2 \mathrm{H}, \mathrm{m}, \mathrm{NH}_{2}\right), 3.34-3.26\left(2 \mathrm{H}, \mathrm{m}, \mathrm{OC}=\mathrm{O}(\mathrm{NH}) \mathrm{CH}_{2} \mathrm{CH}_{2} \mathrm{NH}_{2}\right)$, 3.22-3.14 (2H, m, OC=O(NH) $\left.\mathrm{CH}_{2} \mathrm{CH}_{2} \mathrm{NH}_{2}\right), 2.94(2 \mathrm{H}, \mathrm{t}$, $\left.J=7.5 \mathrm{~Hz},-\mathrm{C}=\mathrm{O}\left(\mathrm{CH}_{2}\right) \mathrm{CH}_{2} \mathrm{CH}_{2}-\right), 2.84-2.75(2 \mathrm{H}, \mathrm{m},-\mathrm{N}<$ $\left.\left(\mathrm{CHHCH}_{2}\right)_{2}>\mathrm{C}\right), 2.5-2.43\left(2 \mathrm{H}, \mathrm{m}, \mathrm{CH}_{2}-\mathrm{N}<\left(\mathrm{CH}_{2} \mathrm{CH}_{2}\right)_{2}>\mathrm{C}\right)$, 2.41-2.31 (2H, m, $\left.-\mathrm{N}<\left(\mathrm{CHHCH}_{2}\right)_{2}>\mathrm{C}\right), 2.01-1.87(4 \mathrm{H}, \mathrm{m}$, $\left.-\mathrm{N}<\left(\mathrm{CH}_{2} \mathrm{CH}_{2}\right)_{2}>\mathrm{C}\right) \cdot{ }^{13} \mathrm{C} \mathrm{NMR}\left(\mathrm{CDCl}_{3}, 100 \mathrm{MHz}\right) 198.38$ $\left(\mathrm{F}-\mathrm{Ar}-\mathrm{C}=\mathrm{OCH}_{2}-\right), 165.64\left(\mathrm{~d}, J_{\mathrm{FC}}=250 \mathrm{~Hz}, \mathrm{Ar}-\mathrm{F}\right.$, (ipso-C) $154.97(\mathrm{O}-\mathrm{C}=\mathrm{O}(\mathrm{NH})-), 143.8(\mathrm{Ar}-\mathrm{Cl},($ para-C$)), 133.67\left(\mathrm{~d}, J_{\mathrm{FC}}=\right.$ $3 \mathrm{~Hz} \mathrm{Ar-F}$ (para-C)), 132.92 (Ar-Cl, (ipso-C)), 130.65 (d, J $J_{\mathrm{FC}}=$ $10.5 \mathrm{~Hz}, \mathrm{Ar}-\mathrm{F}$ (meta-C)), 128.5 (Ar-Cl (meta-C)), 125.99 (Ar-Cl (ortho-C)), 115.62 (d, $J_{\mathrm{FC}}=22.0 \mathrm{~Hz}, \mathrm{Ar}-\mathrm{F}$ (ortho-C)), 78.84 $\left(\left(\mathrm{CH}_{2}\right)_{2}>\mathrm{C}<(\mathrm{O}-)(\mathrm{Ar}-\mathrm{Cl})\right), 57.67\left(\mathrm{CH}_{2} \mathrm{CH}_{2} \mathrm{~N}<\right), 49.27(\mathrm{~N}<$ $\left.\left(\mathrm{CH}_{2}\right)_{2}\left(\mathrm{CH}_{2}\right)_{2}\right), 43.33 \quad\left(\mathrm{CH}_{2} \mathrm{CH}_{2} \mathrm{NH}_{2}\right), 41.75 \quad\left(\mathrm{NHCH}_{2} \mathrm{CH}_{2}\right)$, $36.20\left(\mathrm{C}=\mathrm{O}\left(\mathrm{CH}_{2}\right) \mathrm{CH}_{2}\right), \quad 35.92\left(\left(\mathrm{CH}_{2}\right)_{2} \quad\left(\mathrm{CH}_{2}\right)_{2}>\mathrm{C}<\right), 21.9$ $\left(\mathrm{CH}_{2} \mathrm{CH}_{2} \mathrm{CH}_{2}\right)$.

\subsection{Activation of bis-carboxy PEG with $\mathrm{N}$-hydroxysuccinimide}

Bis-carboxy-PEG $\left(M_{\mathrm{w}} \sim 6000,1 \mathrm{~g}, 167 \mu \mathrm{mol}\right)$ was dissolved in anhydrous $\mathrm{CH}_{2} \mathrm{Cl}_{2}(\sim 20 \mathrm{~mL})$. To this was added, $N$-hydroxysuccinimide (NHS) (3 equiv., $64 \mathrm{mg}, 555 \mu \mathrm{mol}$ ), followed by $N, N^{\prime}$-dicyclohexylcarbodiimide (DCC) (6.45 equiv., $0.222 \mathrm{~g}, 1.1 \mathrm{mmol})$. The reaction was left stirring for 5 hours. Within 30 minutes the reaction had turned cloudy. The reaction mixture was filtered through celite and the filtrate directly added into cold diethyl ether $(500 \mathrm{~mL})$ with vigorous stirring. This precipitated material was left on ice for $1 \mathrm{~h}$, before filtering to recover the white precipitate. The recovered solid was dried under vacuum. The degree of end group activation of the polymer was determined indirectly by measuring the amount of free amine groups remaining after reaction of the activated PEG with an equimolar quantity of the di-peptide gly-gly in borate buffer at $\mathrm{pH}$ 8, using the colorimetric 2,4,6-trinitrobenzene sulfonic acid assay. ${ }^{46}$

\subsection{Synthesis of PEG-haloperidol conjugate}

Haloperidol-AEC (7 equiv., $64 \mathrm{mg}, 139 \mu \mathrm{mol}$ ) was dissolved in anhydrous $\mathrm{CHCl}_{3}(5 \mathrm{~mL})$ and anhydrous $N, N$-diisopropylethylamine (DIPEA) (25 $\mu \mathrm{L}, 139 \mu \mathrm{mol}, 7$ equiv.) was added. NHS-activated PEG (Mw 6308 equiv., 112 mg, $17 \mu \mathrm{mol}$ ) was added portion-wise and the reaction then stirred under a nitrogen atmosphere, protected from light for 3 days. The reaction was monitored in the early stages using RP-HPLC. The solvent was then evaporated in vacuo, to leave $\sim 3 \mathrm{~mL}$, before adding this dropwise to ice cold diethyl ether $(200 \mathrm{~mL})$. The solution was kept on ice for one hour before filtering to recover the fine white precipitate. The solid was then dried in vacuo before dissolving in water $(\sim 10 \mathrm{~mL})$. This was dialysed against distilled water, using a regenerated cellulose membrane of MWCO 1000 Da, with 3 changes of water over a 24 hour period. The product was freeze dried and subjected to RP-HPLC to determine purity. A small amount of free haloperidol-AEC was still present, which resulted in the product needing further purification. PEG-haloperidol-AEC was re-dissolved in around $4 \mathrm{~mL}$ of methanol and loaded on to a LH-20 sephadex column. The column was run using $100 \%$ methanol and fractions containing UV active material (as determined via TLC analysis) were analysed by HPLC. Fractions containing the conjugate were combined, and the methanol removed in vacuo. The residue was dissolved in distilled water and freeze dried once again (yield, 24\%). The conjugate was characterised by ${ }^{1} \mathrm{H}$ and ${ }^{13} \mathrm{C}-\mathrm{NMR}$ spectroscopic analysis, MALDI-TOF mass spectrometry, RP-HPLC and UV absorbance spectrophotometry. The amount of haloperidol bound to the polymer and free drug was determined using ${ }^{1} \mathrm{H}$ NMR spectroscopic analysis and RP-HPLC.

${ }^{1} \mathrm{H}$ NMR $\left(\mathrm{CDCl}_{3}, 500 \mathrm{MHz}\right): 8.03$ (dd, haloperidol-AEC, $J_{\mathrm{ab}}=$ $\left.7.5 \mathrm{~Hz}, J_{\mathrm{aF}}=4.5 \mathrm{~Hz}, \mathrm{Ar}-\mathrm{F}\right), 7.33-7.29$ (m, haloperidol, $\mathrm{Ar}-\mathrm{Cl}$ ), 7.15-7.12 (m, haloperidol, Ar-F), 3.8-3.4 (m, PEG, $\mathrm{CH}_{2} \mathrm{CH}_{2} \mathrm{O}$ ), 3.33-3.29 (m, haloperidol-AEC $\mathrm{NHCH}_{2} \mathrm{CH}_{2} \mathrm{NH}$ ), 3.21-3.15 (m, haloperidol-AEC), 2.60-2.50 (m, PEG and haloperidol-AEC), 
2.25-2.00 (m, haloperidol-AEC). ${ }^{13} \mathrm{C} \mathrm{NMR}\left(\mathrm{CDCl}_{3}, 125 \mathrm{MHz}\right)$ 173.16 ( $\mathrm{PEG},-\mathrm{CH}_{2} \mathrm{C}=\mathrm{O}(\mathrm{OH})$ ), $172.93\left(\mathrm{PEG}, \mathrm{NHC}=\mathrm{O}\left(\mathrm{CH}_{2}\right)^{-}\right)$, $165.82\left(\mathrm{~d}, J_{\mathrm{FC}}=253.0 \mathrm{~Hz}\right.$, haloperidol-AEC, Ar-F, (ipso-C)), 154.92 (haloperidol-AEC, $-\mathrm{OC}=\mathrm{O}(\mathrm{NH})-$ ), 133.25 (haloperidolAEC, Ar-Cl, (ipso-C)), 130.76 (d, $J_{\mathrm{FC}}=9.5 \mathrm{~Hz}$, haloperidol-AEC, $\mathrm{Ar}-\mathrm{F}$ (meta-C)), 128.64 (haloperidol-AEC, Ar-Cl (meta-C)), 126.04 (haloperidol-AEC, Ar-Cl (ortho-C)), 115.75 (haloperidolAEC, d, $J_{\mathrm{FC}}=20.5 \mathrm{~Hz}, \mathrm{Ar}-\mathrm{F}$ (ortho-C)), 72.57 (haloperidol-AEC, $\left.\left(\mathrm{CH}_{2}\right)_{2}>\mathrm{C}<(\mathrm{O})(\mathrm{Ar}-\mathrm{Cl})\right), 70.55\left(\mathrm{PEG},-\left(\mathrm{OCH}_{2} \mathrm{CH}_{2}\right)_{n}\right), 56.83$ (haloperidol-AEC, $\left(\mathrm{CH}_{2} \mathrm{CH}_{2} \mathrm{~N}<\right)$ ), 48.62 (haloperidol-AEC, $\mathrm{N}<$ $\left.\left(\mathrm{CH}_{2}\right)_{2}\left(\mathrm{CH}_{2}\right)_{2}\right), 40.23\left(\mathrm{PEG}, \mathrm{NHCH}_{2} \mathrm{CH}_{2}\left(\mathrm{OCH}_{2} \mathrm{CH}_{2}\right)_{n}\right), 39.6$ (haloperidol-AEC, $\left(\mathrm{CH}_{2}\right)_{2}\left(\mathrm{CH}_{2}\right)_{2}>\mathrm{C}<$ ), 39.24 (haloperidol-AEC,$\mathrm{NHCH}_{2} \mathrm{CH}_{2} \mathrm{NH}-$ ), 39.24 (haloperidol-AEC, $-\mathrm{NHCH}_{2} \mathrm{CH}_{2} \mathrm{NH}-$ ), 36.09 (haloperidol-AEC, $\left.\mathrm{C}=\mathrm{O}\left(\mathrm{CH}_{2}\right) \mathrm{CH}_{2}\right), 32.13$ (PEG, $\left.\mathrm{C}=\mathrm{OCH}_{2} \mathrm{CH}_{2} \mathrm{C}=\mathrm{O}\right), \quad 31.95 \quad\left(\mathrm{PEG}, \quad \mathrm{C}=\mathrm{OCH}_{2} \mathrm{CH}_{2} \mathrm{C}=\mathrm{O}(\mathrm{OH})\right.$ ), 29.69 (PEG, $-\mathrm{CH}_{2} \mathrm{CH}_{2} \mathrm{C}=\mathrm{O}(\mathrm{OH})$ ), 28.13 (haloperidol-AEC, $\mathrm{CH}_{2} \mathrm{CH}_{2} \mathrm{CH}_{2}$ ).

\subsection{RP-HPLC analysis of PEG-haloperidol}

PEG-haloperidol was analysed using RP-HPLC with a $\mathrm{C}_{18}$

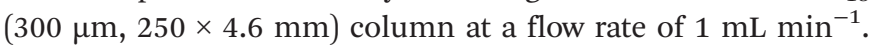
The eluent was: A; acetonitrile and B; water containing $0.25 \%$ acetic acid. The protocol for analysis of PEG-haloperidol comprised UV absorbance detection at $254 \mathrm{~nm}$, using a gradient of $10 \%$ A increasing to $70 \%$ A over 25 minutes, returning to $10 \% \mathrm{~A}$ in the following 10 minutes with a total run time of 40 minutes.

\subsection{MALDI-TOF}

For MALDI-TOF analysis sample solutions at a concentration of $5 \mathrm{mg} \mathrm{mL} \mathrm{mL}^{-1}$ at a $1: 1: 1$ ratio with dithranol $\left(40 \mathrm{mg} \mathrm{mL}^{-1}\right.$, THF) and sodium trifluoroacetate $\left(10 \mathrm{mg} \mathrm{mL} \mathrm{m}^{-1}\right.$, THF $)$ as matrix were employed. Linear positive mode was used on a Bruker Ultraflex MALDI-TOF/TOF mass spectrometer with an acceleration voltage of $25 \mathrm{kV}$.

\subsection{Stability of PEG-haloperidol under physiological conditions}

Stability studies of PEG-haloperidol were carried out in rat plasma. Briefly, $22 \mu \mathrm{L}$ of either free haloperidol or PEG-haloperidol conjugate solution was added to $200 \mu \mathrm{L}$ of rat plasma, before vortexing for $1 \mathrm{~min}$ to ensure complete mixing.

$200 \mu \mathrm{l}$ of rat plasma was aliquoted out, and to this $22 \mu \mathrm{l}$, of either, free haloperidol or PEG-haloperidol conjugate, solution was added. This was vortexed for $1 \mathrm{~min}$ to ensure complete mixing.

Mixtures were then divided into five equal aliquots for analysis via HPLC at $0 \mathrm{~h}, 48 \mathrm{~h}, 24 \mathrm{~h}, 72 \mathrm{~h}$ and $168 \mathrm{~h}$. The samples were incubated at $37^{\circ} \mathrm{C}$ to mimic physiological temperatures. At the appropriate time point samples were removed from incubation and quenched with $160 \mu \mathrm{l}$ of, $1: 1$, acetonitrile: methanol. This was then vortexed for $1 \mathrm{~min}$, followed by centrifugation at $3500 \mathrm{rpm}$ for $2 \mathrm{~min}$. This supernatant was removed and filtered through a $0.45 \mu \mathrm{m}$ syringe filter. The filtered supernatant was then analysed via HPLC, using the elution programme outlined in section 4.6.

\subsection{Radioligand binding studies}

Cell membranes $(25 \mu \mathrm{g})$, of cells from CHO expressing the $\mathrm{D}_{2}$ receptor, were incubated with $\left[{ }^{3} \mathrm{H}\right]$ spiperone $(0.25 \mathrm{nM})$ and competing drugs in HEPES buffer (20 mM HEPES, $1 \mathrm{mM}$ EGTA, $1 \mathrm{mM}$ EDTA, $10 \mathrm{mM} \mathrm{MgCl}_{2}$, pH 7.4 (using $\mathrm{HCl}$ ) containing $0.1 \mathrm{mM}$ dithiothreitol) in a final volume of $1 \mathrm{ml}$ for $3 \mathrm{~h}$ at $25{ }^{\circ} \mathrm{C}$. The assay was terminated by rapid filtration (through Whatman GF/C filters) using a Brandel cell harvester, followed by four washes with $4 \mathrm{ml}$ ice-cold phosphate-

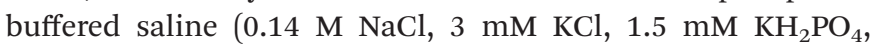
$\left.5 \mathrm{mM} \mathrm{Na} \mathrm{HPO}_{4} ; \mathrm{pH} 7.4\right)$ to remove unbound radioactivity. Filters were soaked in $2 \mathrm{ml}$ of scintillation fluid for at least $5 \mathrm{~h}$ and bound radioactivity was determined by liquid scintillation counting. Non-specific binding of $\left[{ }^{3} \mathrm{H}\right]$ spiperone was determined in the presence of $3 \mu \mathrm{M}(+)$-butaclamol. The data was analysed using GraphPad Prism software, version 5.04 and fitted to equations describing a one-site binding model. $\mathrm{p} K_{\mathrm{i}}$ values for the data were obtained from non-linear regression.

\subsection{Theoretical modelling to assess the ability of PEG} conjugation to restrict passage haloperidol across the BBB

The following equation proposed by $\mathrm{Fu}$ et al. ${ }^{36}$ was used to predict the BBB penetration of the free ligands and PEG-ligand conjugates.

$$
\begin{aligned}
\log \mathrm{BB}= & -9.880 \times 10^{-6} M_{\mathrm{w}}^{2}+7.339 \times 10^{-3} M_{\mathrm{w}} \\
& -0.2268 n_{\mathrm{pol}}-0.1143
\end{aligned}
$$

The components of the model are defined as follows: $\log \mathrm{BB}=\log$ arithm of the ratio of the steady state concentration of the compound in the brain to the concentration of compound in the blood, $M_{\mathrm{w}}=$ molecular weight, $n_{\mathrm{pol}}=$ the number of polar atoms (oxygen, nitrogen and attached hydrogen).

The model was developed using 86 compounds, of which 8 were removed as outliers. The correlation coefficient for the 78 remaining compounds was, $r^{2}=0.74 .^{36}$

\section{Acknowledgements}

We would like to thank the Engineering and Physical Sciences Research Council (EPSRC Grant EP/H021477/1) for financial support. The authors also thank Peter Heath for help with the acquisition of NMR spectra, Dr Olga Khutoryanskaya for assistance with the conjugate stability studies and Dr Davinia Mills for support with the MALDI-TOF analysis. We would also like to thank the University of Reading for use of the Chemical Analysis Facility.

\section{References}

1 J. A. Borovac, Yale J. Biol. Med., 2016, 89, 37-47.

2 P. Dietrichson, J. Presthus and R. Holmsen, Eur. Neurol., 1975, 13, 339-349.

3 F. E. R. Simons, Clin. Exp. Allergy, 1999, 29, 125-132. 
4 I. Hindmarch, Z. Shamsi and S. Kimber, Clin. Exp. Allergy, 2002, 32, 133-139.

5 N. J. Abbott, J. Inherited Metab. Dis., 2013, 36, 437-449.

6 W. M. Pardridge and L. J. Mietus, J. Clin. Invest., 1979, 64, 145-154.

7 W. M. Pardridge, Drug Discovery Today, 2007, 12, 54-61.

8 R. Satchi-Fainaro, M. Puder, J. W. Davies, H. T. Tran, D. A. Sampson, A. K. Greene, G. Corfas and J. Folkman, Nat. Med., 2004, 10, 255-261.

9 JAMA, J. Am. Med. Assoc., 2016, 315, 194-195.

10 J. Yang and J. Kopecek, J. Controlled Release, 2014, 190, 288-303.

11 T. W. Chu and J. Kopecek, Biomater. Sci., 2015, 3, 908-922.

12 W. A. Banks, BMC Neurol., 2009, 9, S3.

13 R. A. Williamson, S. Worrall, P. L. Chazot and P. G. Strange, EMBO J., 1988, 7, 4129-4133.

14 T. Etrych, J. Strohalm, M. Šírová, B. Tomalová, P. Rossmann, B. Ríhová, K. Ulbrich and M. Kovář, Polym. Chem., 2015, 6, 160-170.

15 F. M. Veronese, O. Schiavon, G. Pasut, R. Mendichi, L. Andersson, A. Tsirk, J. Ford, G. Wu, S. Kneller, J. Davies and R. Duncan, Bioconjugate Chem., 2005, 16, 775-784.

16 F. Greco and M. J. Vincent, Front. Biosci., 2008, 13, 27442756.

17 R. Duncan, Nat. Rev. Cancer, 2006, 6, 688-701.

18 A. S. Mikhail and C. Allen, Biomacromolecules, 2010, 11, 1273-1280.

19 H. Hall, G. Sedvall, O. Magnusson, J. Kopp, C. Halldin and L. Farde, Neuropsychopharmacol., 1994, 11, 245-256.

20 N.-E. Anden, A. Carlsson, A. Dahlstrom, K. Fuxe, N.-A. Hillarp and K. Larsson, Life Sci., 1964, 3, 523-530.

21 J.-M. Beaulieu and R. R. Gainetdinov, Pharmacol. Rev., 2011, 63, 182-217.

22 C. C. Felder, A. M. Mckelvey, M. S. Gitler, G. M. Eisner and P. A. Jose, Kidney Int., 1989, 36, 183-193.

23 A. Eliassi, F. Alealli and T. Ghasemi, Clin. Exp. Pharmacol. Physiol., 2008, 35, 1065-1070.

24 C. Missale, S. Russell Nash, W. W. Robinson, M. Jaber and M. G. Caron, Physiol. Rev., 1998, 78, 189-225.

25 W. B. Liechty, D. R. Kryscio, B. V. Slaughter and N. A. Peppas, Annu. Rev. Chem. Biomol. Eng., 2010, 1, 149-173.

26 G. Pasut and F. M. Veronese, Prog. Polym. Sci., 2007, 32, 933-961.
27 M. Hans, K. Shimoni, D. Danino, S. J. Siegel and A. Lowman, Biomacromolecules, 2005, 6, 2708-2717.

28 M. L. Hans, C. Maxwell, R. S. Ehrlichman, K. Metzger, Y. Liang, S. J. Siegel and A. M. Lowman, J. Biomed. Mater. Res., Part B, 2007, 83B, 422-430.

29 A. Mukherjee, T. K. Prasad, N. M. Rao and R. Banerjee, J. Biol. Chem., 2005, 280, 15619-15627.

30 K. Pal, S. K. Pore, S. Sinha, R. Janardhanan, D. Mukhopadhyay and R. Banerjee, J. Med. Chem., 2011, 54, 2378-2390.

31 F. Bettio, M. Canevari, C. Marzano, F. Bordin, A. Guiotto, F. Greco, R. Duncan and F. M. Veronese, Biomacromolecules, 2006, 7, 3534-3541.

32 F. M. H. de Groot, L. W. A. Van Berkom and H. W. Sheeren, J. Med. Chem., 2000, 43, 3093-3102.

33 V. A. Levin, J. Med. Chem., 1980, 23, 682-684.

34 W. M. Pardridge, Adv. Drug Delivery Rev., 1995, 15, $5-36$.

35 M. M. Almutairi, C. Gong, Y. G. Xu, Y. Chang and H. Shi, Cell. Mol. Life Sci., 2016, 73, 57-77.

36 X.-C. Fu, G.-P. Wang, H.-L. Shan, W.-Q. Liang and J.-Q. Gao, Eur. J. Pharm. Biopharm., 2008, 70, 462-466.

37 F. Lopez-Munoz and C. Alamo, Brain Res. Bull., 2009, 79, 130-141.

38 K. Iwaki, T. Sakaeda, M. Kakumoto, T. Nakamura, C. Komoto, N. Okamura, et al., J. Pharm. Pharmacol., 2006, 58, 1617-1622.

39 J. S. Wang, H. J. Zhu, J. S. Markowitz, J. L. Donovan, H. J. Yuan and C. L. DeVane, Basic Clin. Pharmacol. Toxicol., 2008, 103, 336-341.

40 Q. Shena, Y. Lina, T. Handaa, M. Doia, M. Sugiea, et al., Int. J. Pharm., 2006, 313, 49-56.

41 M. W. Howe and D. A. Dombeck, Nature, 2016, 535, 505510.

42 D. R. Sibley, Annu. Rev. Pharmacol. Toxicol., 1999, 39, 313-341.

43 S. D. Iversen and L. L. Iversen, Trends Neurosci., 2007, 30, 188-193.

44 R. A. Bressen and J. A. Crippa, Acta. Pyschiatr. Scand., 2005, 111, 14-21.

45 J. J. Gildea, I. T. Shah, R. E. Van Sciver, J. A. Israel, C. Enzensperger, H. E. McGrath, P. A. Jose and R. A. Felder, Kidney Int., 2014, 86, 118-126.

46 S. L. Snyder and P. Z. Sobocinski, Anal. Biochem., 1975, 64, 284-288. 